\title{
Cardiac impact of inhaled therapy in the largest randomised placebo-controlled trial in COPD history: have we reached the SUMMIT?
}

\author{
Stefan Andreas ${ }^{1,2}$, Christer Janson ${ }^{3}$, Maarten van den Berge ${ }^{4}$ and \\ Lies Lahousse ${ }^{5,6}$
}

Affiliations: ${ }^{1}$ Cardiology and Pneumology, University Medical Center Göttingen, Göttingen, Germany. ${ }^{2}$ Lung Clinic Immenhausen, Immenhausen, Germany. ${ }^{3}$ Dept of Medical Sciences: Respiratory, Allergy and Sleep Research, Uppsala University, Uppsala, Sweden. ${ }^{4}$ University of Groningen, University Medical Center Groningen, Dept of Pulmonary Diseases, Groningen, The Netherlands. ${ }^{5}$ Dept of Respiratory Medicine, Ghent University Hospital, Ghent, Belgium. ' Dept of Epidemiology, Erasmus Medical Center, Rotterdam, The Netherlands.

Correspondence: Stefan Andreas, Abteilung Kardiologie und Pneumologie, Universitätsmedizin Göttingen, 37075 Göttingen, Germany. E-mail: stefan.andreasamed.uni-goettingen.de

@ERSpublications

SUMMIT supports the efficiency and cardiovascular safety of LABA and ICS in COPD patients at cardiovascular risk http://ow.ly/p6Is300ffoc

\section{Background}

Chronic obstructive pulmonary disease (COPD) is a major cause of death and disability worldwide. Although COPD primarily affects the lungs, it has become clear that systemic effects of COPD significantly contribute to its severity and overall mortality. Due to its high prevalence in the older population, and smoking as a shared risk factor, cardiovascular disease (CVD) is of particular importance [1]. Indeed, more patients with COPD die from CVD than from COPD itself [2-5]. Research indicates a number of mechanisms that explain this relationship, including systemic inflammation, physical inactivity, neurohumoural activation, arrhythmias, endothelial dysfunction and a greater fall in pleural pressure during inspiration [6]. Thus, bronchodilation might positively impact on CVD. In line with that reasoning, endothelial function and blood pressure were improved after lung volume reduction surgery in patients with severe COPD [7]. Furthermore, retrospective data from the National Emphysema Treatment Trial suggest that long-acting $\beta_{2}$-agonists (LABA) reduce mortality [8]. There are also data suggesting that inhaled corticosteroids (ICS) may have a beneficial effect on the risk of cardiovascular events in COPD, possibly by decreasing systemic inflammation [9].

Besides the well-characterised positive effects of inhaled therapy, safety issues remain. Both LABA and long-acting muscarinic antagonists (LAMA), as well as fixed combinations of both, and the combination of ICS and LABA, seem to be safe when used in the appropriate dose in patients with stable CVD [10, 11]. However, the cardiac safety of LABA and LAMA is less evident when used in COPD patients with uncontrolled, substantial or acute CVD [10]. Therefore, the Study to Understand Mortality and Morbidity in COPD (SUMMIT), focusing on COPD patients with increased cardiovascular risk, was well positioned to inform us of the cardiovascular safety and effects of ICS and LABA.

Received: May 022016 | Accepted after revision: May 122016

Support statement: We acknowledge the U4 university network between the Universities of Ghent, Göttingen, Groningen and Uppsala. Lies Lahousse is a Postdoctoral Fellow of the Research Foundation-Flanders (FWO). Funding information for this article has been deposited with the Open Funder Registry.

Conflict of interest: Disclosures can be found alongside this article at openres.ersjournals.com

Copyright $\odot$ ERS 2016. This article is open access and distributed under the terms of the Creative Commons Attribution Non-Commercial Licence 4.0. 


\section{Design and endpoints}

SUMMIT is a placebo-controlled, double-blind, randomised, parallel-group, multicentre trial [6]. COPD patients with moderate airflow limitation $\left(\geqslant 50 \%\right.$ and $\leqslant 70 \%$ predicted forced expiratory volume in $\left.1 \mathrm{~s}\left(\mathrm{FEV}_{1}\right)\right)$ and a history of CVD or increased risk of CVD were randomised 1:1:1:1 to one of four double-blind treatment groups: placebo, fluticasone furoate (FF), vilanterol (VI), or a combination of FF and VI [6]. This was an endpoint-driven study designed to have $90 \%$ power to detect a $30 \%$ reduction in all-cause mortality with FF/VI compared to placebo [6]. Clinical events were adjudicated meticulously by an endpoint committee. With $>16000$ patients included, the primary endpoint, all-cause mortality, showed a $12 \%$ relative reduction with FF/VI compared to placebo, which was not statistically significant $(p=0.137)$ [12]. The predefined secondary endpoints were 1) the effect of FF/VI compared with placebo on the rate of decline in FEV1, and 2) the effect of FF/VI compared with placebo on a cardiovascular composite endpoint comprised of on-treatment cardiovascular death, myocardial infarction, stroke, unstable angina and transient ischaemic attack [6]

Combination therapy reduced the secondary endpoint, rate of FEV1 decline, by $8 \mathrm{~mL}$ per year compared with placebo $(p=0.019)$ [12]. When analysing the monotherapy arms, this effect was related to the inhaled corticosteroid use rather than the $\beta_{2}$-agonist use (table 1). For the other secondary endpoint, the risk of cardiovascular events was not significantly different between FF/VI and placebo $(p=0.478)$ [12]. It must be kept in mind, however, that these were secondary endpoints and the primary endpoint was negative, thus making inferences problematic.

Other prespecified endpoints demonstrated an improvement compared to placebo in the rate of moderate and severe exacerbations (table 1). There was no difference between the treatment groups in pneumonia and other adverse events. Analysis of subgroups such as patients with atrial fibrillation or a myocardial infarction are ongoing and are likely to be available in subsequent publications.

\section{Comments}

The SUMMIT trial is the largest COPD randomised, placebo-controlled trial ever. The study investigators report a negative finding, albeit that the direction of effect was as anticipated. SUMMIT was designed to have $90 \%$ power to detect a $30 \%$ reduction in the risk of all-cause mortality on FF/VI compared with placebo [6]. This assumption might have been too optimistic. ClinicalTrials.gov and other resources [6] do not inform us about previous studies that led to this assumption. Two preceding large studies $[4,13]$ with mortality signals included patients with more severe COPD and less cardiovascular risk, making inferences for SUMMIT challenging.

Physicians are often hesitant to treat airway obstruction with inhaled LABA in patients with CVD [14]. The currently presented data of the large and meticulously controlled SUMMIT trial in a moderately dyspnoeic COPD population at increased cardiovascular risk do not indicate major signals for cardiac safety. These important and timely data should reassure physicians on the use of LABA in moderate COPD patients at cardiovascular risk in general. However, questions on subgroups such as patients with atrial fibrillation or recent myocardial infarction remain, and this clinical relevant information is be eagerly awaited.

By their systemic effects, concurrent use of LABA and LAMA, i.e. dual bronchodilation, might potentially increase cardiovascular effects [10]. Recent phase III studies of dual bronchodilators (some of them using Holter data) did not exhibit conclusive safety signals $[10,15,16]$. However, these trials were smaller than SUMMIT and have not investigated a cohort with increased cardiovascular risk. SUMMIT did not permit tiotropium at baseline but following severe exacerbation, tiotropium could be added. Therefore, SUMMIT

\section{TABLE 1 Main results of the SUMMIT trial}

\begin{tabular}{|c|c|c|c|c|c|}
\hline & Placebo & FF & VI & $\mathrm{FF} / \mathrm{VI}$ & p-value $\#$ \\
\hline Mortality & $275(6.7 \%)$ & $251(6.1 \%)$ & $265(6.4 \%)$ & $246(6.0 \%)$ & 0.137 \\
\hline FEV 1 decline $\mathrm{mL} \cdot \mathrm{year}^{-1}$ mean $\pm \mathrm{SE}$ & $46 \pm 2.5$ & $38 \pm 2.4$ & $47 \pm 2.4$ & $38 \pm 2.4$ & 0.019 \\
\hline Moderate and severe exacerbations per year & 0.35 & 0.31 & 0.31 & 0.25 & $<0.0001$ \\
\hline Severe exacerbations per year & 0.07 & 0.06 & 0.06 & 0.05 & 0.0004 \\
\hline Pneumonia cases per 100 person-years & 3.8 & 4.2 & 2.8 & 3.9 & $>0.05$ \\
\hline
\end{tabular}

SUMMIT: Study to Understand Mortality and Morbidity in COPD; FF: fluticasone furoate; VI: vilanterol; FEV1: forced expiratory volume in $1 \mathrm{~s}$. \#: FF/VI compared to placebo; " : on-treatment cardiovascular death, myocardial infarction, stroke, unstable angina and transient ischaemic attack. 
TABLE 2 Comparison between the three largest randomised placebo-controlled trials in chronic obstructive pulmonary disease (COPD) history: SUMMIT, TORCH and UPLIFT

\begin{tabular}{|c|c|c|c|}
\hline & SUMMIT & TORCH & UPLIFT \\
\hline First author [ref.], year & VESTBo [12], 2016 & CALVERLEY [4], 2007 & TASHKIN [23], 2008 \\
\hline Duration years & Median 1.8 & 3 & 4 \\
\hline Subjects & 16485 ITT (16568 total) & 6112 (6184 in post hoc analysis) & 5993 (5994 in post hoc analysis) \\
\hline \multirow[t]{6}{*}{ Inclusion criteria } & COPD II & COPD II-III & COPD \\
\hline & Age $40-80$ years & Age $40-80$ years & Age $\geqslant 40$ years \\
\hline & $\geqslant 10$ pack-years & $\geqslant 10$ pack-years & $\geqslant 10$ pack-years \\
\hline & $\begin{array}{c}\mathrm{FEV}_{1} / \mathrm{FVC}<70 \% \text {, and post-BD FEV } 1 \geqslant 50 \\
\text { and } \leqslant 70 \% \text { pred }\end{array}$ & $\begin{array}{c}\mathrm{FEV}_{1} / \mathrm{FVC} \leqslant 70 \% \text { and pre-BD } \mathrm{FEV} 1<60 \% \\
\text { pred with poor reversibility }\end{array}$ & $\begin{array}{c}\mathrm{FEV}_{1} / \mathrm{FVC} \leqslant 70 \% \text { at visits } 1 \text { and } 2 \text {, and } \\
\text { post-BD FEV } 1 \leqslant 70 \% \text { pred }\end{array}$ \\
\hline & $\mathrm{mMRC} \geqslant 2$ & Able to use inhaler and relief medication correctly & Able to use inhaler and perform \\
\hline & $\begin{array}{l}\text { History or increased risk of } \\
\text { cardiovascular disease }^{\#}\end{array}$ & Women unable to conceive & $\begin{array}{c}\text { acceptable PFTs } \\
\text { Maintained on stable respiratory } \\
\text { medications }\end{array}$ \\
\hline \multirow[t]{10}{*}{ Exclusion criteria } & $\begin{array}{c}\text { Asthma or current other respiratory } \\
\text { disorders }\end{array}$ & $\begin{array}{l}\text { Asthma or current other respiratory disorders } \\
\text { Positive chest radiography in the last } 6 \text { months }\end{array}$ & $\begin{array}{c}\text { Asthma or other respiratory disorders } \\
\text { Pulmonary resection }\end{array}$ \\
\hline & Positive chest radiography & LVRS & LVRS \\
\hline & LVRS & Lung transplant & Lung transplant \\
\hline & Lung transplant & $\alpha_{1}$-antitrypsin deficiency & LTOT \\
\hline & $\alpha_{1}$-antitrypsin deficiency & LTOT & Drug (component) hypersensitivity \\
\hline & LTOT & LTOC & Recent other investigational drugs \\
\hline & LTOC & Recent other investigational drugs & Oral corticosteroid use at unstable \\
\hline & Exacerbation during run-in period & Drug (component) hypersensitivity & doses or $\geqslant 10 \mathrm{mg} \cdot$ day $^{-1}$ \\
\hline & & Exacerbation during run-in period & $\begin{array}{l}\text { Exacerbation before or } \\
\text { during run-in period }\end{array}$ \\
\hline & & & $\begin{array}{c}\text { Women able to conceive, pregnant or } \\
\text { nursing }\end{array}$ \\
\hline Specific disease exclusion criteria & $\begin{array}{l}\text { Current severe heart failure (NYHA } \\
\text { class IV, ejection fraction }<30 \% \text { ) } \\
\text { ICD } \\
\text { End-stage chronic renal disease }\end{array}$ & $\begin{array}{c}\text { Serious, uncontrolled disease or psychological } \\
\text { disorders likely to interfere results or to } \\
\text { cause death within } 3 \text { years } \\
\text { Alcohol, drug or solvent abuse }\end{array}$ & $\begin{array}{l}\text { Significant diseases likely to interfere } \\
\text { results or participants' participation } \\
\text { History of myocardial infarction (within } \\
\text { last } 6 \text { months) }\end{array}$ \\
\hline & $\begin{array}{l}\text { Conditions other than vascular disease } \\
\text { or COPD likely to cause death within }\end{array}$ & & $\begin{array}{l}\text { Cardiac arrhythmia or heart failure } \\
\text { hospitalisation (in the last year) }\end{array}$ \\
\hline & 3 years or study incompletion & & Renal impairment \\
\hline & & & Malignancy \\
\hline & & & NAG \\
\hline & & & Symptomatic BPH or PBNO \\
\hline & & & Alcohol or abuse (within the last year) \\
\hline
\end{tabular}


TABLE 2 Continued

\section{SUMMIT}

\section{Comparator}

\section{Drug of investigation}

Third arm

Fourth arm

Device

Primary endpoint

Cardiac/mortality endpoint
Placebo lall prior use of ICS and

LABA/LAMA discontinued)

Vilanterol $25 \mu \mathrm{g}$ plus fluticasone furoate $100 \mu \mathrm{g}$

Vilanterol $25 \mu \mathrm{g}$

Fluticasone furoate $100 \mu$

Novel dry-powder inhaler

All-cause mortality (negative)

All-cause mortality ( $p=0.137)$ and composite cardiovascular endpoint ( $p=0.478$ ) were not significantly decreased for combination therapy

compared to placebo

\section{TORCH}

UPLIFT

Placebo (SABA/SAMA, theophyllines, smoking cessation therapy, intermittent oxygen therapy and short courses of oral corticosteroids permitted Salmeterol xinafoate $50 \mu \mathrm{g}$ plus fluticasone propionate $500 \mu \mathrm{g}$

Salmeterol xinafoate $50 \mu \mathrm{g}$

Fluticasone propionate $500 \mu$ All Diskus/Accuhaler

All-cause mortality (negative)

All-cause mortality was numerically lower for combination therapy or salmeterol compared to placebo Mortality in fluticasone group was numerically higher Post hoc analysis: salmeterol alone or in combination did not increase the risk of cardiovascular events
Placebo luse of all respiratory

medications except inhaled anticholinergic drugs permitted] Tiotropium $18 \mu \mathrm{g}$

HandiHaler, twice daily Rate of decline in trough and $90-\mathrm{min}$ post-BD FEV1 (negative)

Cardiac AEs lower in tiotropium

treated except for angina and cardiac failure

Mortality lower in tiotropium group $(14.4 \%)$ versus placebo $(16.3 \%)$

Post hoc analysis: decreased cardiac mortality in tiotropium treated

SUMMIT: Study to Understand Mortality and Morbidity in COPD; TORCH: Towards a Revolution in COPD Health; UPLIFT: Understanding Potential Long-term Impacts on Function with Tiotropium; ITT: intention to treat. FEV1: forced expiratory volume in 1 s. FVC: forced vital capacity; BD: bronchodilator: mMRC: modified Medical Research Council dyspnoea score: PFT. pulmonary function test; LVRS: lung volume reduction surgery; LTOT: long-term oxygen therapy; LTOC: long-term oral corticosteroid therapy; NYHA: New York Heart Association; ICD: implantable cardioverter defibrillator; NAG: narrow-angle glaucoma; BPH: benign prostatic hyperplasia; PBNO: primary bladder-neck obstruction; ICS: inhaled corticosteroids; LABA: long-acting $\beta_{2}$-agonists; LAMA: long-acting muscarinic antagonists; SABA: short-acting $\beta_{2}$-agonists; SAMA: short-acting muscarinic antagonists; AE: adverse event. \#: established coronary artery disease, established peripheral vascular disease, previous stroke, previous myocardial infarction or diabetes mellitus with target organ disease, or if $\geqslant 60$ years of age and receiving medication for two or more of hypercholesterolaemia, hypertension, diabetes mellitus or peripheral vascular disease. 
provides only limited data on dual bronchodilation and thus is unable to comment on safety issues of LABA plus LAMA.

The improvement in FEV1 and the reduction of moderate and severe exacerbations with FF, VI and FF/VI confirms effects that were seen in previous studies, such as TORCH (Towards a Revolution in COPD Health) and a meta-analysis [4, 16]. Besides, the effect of FF/VI on FEV1 was smaller than in trials evaluating dual bronchodilation $[10,15,16]$. Effects on quality of life were not reported.

SUMMIT is the largest study showing a reduction in the rate of FEV1 decline in a predefined analysis. As discussed above, secondary endpoints in a study with a negative primary endpoint have to be interpreted with caution. Nevertheless, clinically, it is reasonable to assume that the two endpoints are independent of each other since a small effect on the rate of FEV1 decline $(8 \mathrm{~mL}$ per year) will not impact mortality. However, it is questionable whether this small difference observed over a relatively short time period (median study exposure 1.8 years) has clinical relevance, especially since recent trials show clinically relevant effects of dual bronchodilation compared to salmeterol plus fluticasone [17]. Further studies might define subgroups where ICS affect disease progression, such as in COPD patients with blood eosinophilia or a Th2 gene expression profile [18-20]. Unfortunately, blood eosinophils were not routinely evaluated in SUMMIT.

Compared to placebo, the combination treatment had no significant effect on the incidence of pneumonia in SUMMIT [12]. This is in contrast with previous studies and a meta-analysis [21, 22]. This contrast might be explained by the different patient characteristics or different inclusion and exclusion criteria (table 2). Lung function was less compromised (higher FEV1) and CVD more common in SUMMIT participants than in previous large COPD cohorts (table 2) $[24,25]$. The relatively low dose of the ICS may also have been beneficial because the pneumonia risk is dose dependent [24]. In line with ICS meta-analyses, the phase III COPD studies using FF/VI showed increased pneumonia rates with increasing FF dose $[21,24]$. Finally, the relatively short mean follow-up might also have contributed to the observed pneumonia rates in SUMMIT [12, 24].

Was the therapy used in SUMMIT the optimal inhaled treatment? A recent trial available only as press release shows a reduction in exacerbations with the dual bronchodilator indacaterol/glycopyrronium as compared to the LABA/ICS salmeterol/fluticasone [17]. The press release does not clarify whether this finding is driven by the reduction of severe, moderate or mild (mainly lung function driven) exacerbations, but it would be interesting to know what the effects of dual bronchodilation in a SUMMIT-like population are. However, given that inhaled therapy in COPD improves convincing clinical endpoints such as lung function, exacerbations, exercise capacity and quality of life, another large placebo-controlled bronchodilator study with mortality as the primary endpoint is unlikely to be performed for ethical and financial reasons $[4,23]$. In this regard, it appears that we have reached the summit.

Similar to previous COPD trials, $47 \%$ of the SUMMIT patients were active smokers [12]. Smoking cessation is the most effective way to reduce pulmonary as well as cardiovascular morbidity and mortality, and thus remains of principal importance in COPD treatment [26].

\section{Conclusion}

SUMMIT clearly supports the efficiency and cardiovascular safety of LABA and ICS in COPD patients at cardiovascular risk. Subsequent subgroup analysis is likely to provide further important information. Nevertheless, diagnosing and targeting underlying CVD might be a more effective way to address mortality in COPD. Accordingly, $\beta$-blockade and angiotensin receptor blockade targeting neurohumoural activation, as is present in COPD, shows promise [3,27].

\section{References}

1 Chen W, Thomas J, Sadatsafavi M, et al. Risk of cardiovascular comorbidity in patients with chronic obstructive pulmonary disease: a systematic review and meta-analysis. Lancet Respir Med 2015; 3: 631-639.

2 Anthonisen NR, Skeans MA, Wise RA, et al. The effects of a smoking cessation intervention on 14.5-year mortality: a randomized clinical trial. Ann Intern Med 2005; 142: 233-239.

3 Decramer M, Janssens W. Chronic obstructive pulmonary disease and comorbidities. Lancet Respir Med 2013; 1: 73-83.

4 Calverley PM, Anderson JA, Celli B, et al. Salmeterol and fluticasone propionate and survival in chronic obstructive pulmonary disease. N Engl J Med 2007; 356: 775-789.

5 Lahousse L, Loth DW, Joos GF, et al. Statins, systemic inflammation and risk of death in COPD: the Rotterdam study. Pulm Pharmacol Ther 2013; 26: 212-217.

6 Vestbo J, Anderson J, Brook RD, et al. The Study to Understand Mortality and Morbidity in COPD (SUMMIT) study protocol. Eur Respir J 2013; 41: 1017-1022.

7 Clarenbach CF, Sievi NA, Brock M, et al. Lung volume reduction surgery and improvement of endothelial function and blood pressure in patients with chronic obstructive pulmonary disease. A randomized controlled trial. Am J Respir Crit Care Med 2015; 192: 307-314. 
8 Horita N, Miyazawa N, Morita S, et al. Long-acting beta-agonists reduce mortality of patients with severe and very severe chronic obstructive pulmonary disease: a propensity score matching study. Respir Res 2013; 14: 62.

9 Lofdahl CG, Postma DS, Pride NB, et al. Possible protection by inhaled budesonide against ischaemic cardiac events in mild COPD. Eur Respir J 2007; 29: 1115-1119.

10 Lahousse L, Verhamme KM, Stricker BH, et al. Cardiac effects of current treatments of chronic obstructive pulmonary disease. Lancet Respir Med 2016; 4: 149-164.

11 Dong $\mathrm{YH}$, Chang $\mathrm{CH}$, Gagne JJ, et al. Comparative cardiovascular and cerebrovascular safety of inhaled long-acting bronchodilators in patients with chronic obstructive pulmonary disease: a population-based cohort study. Pharmacotherapy 2016; 36: 26-37.

12 Vestbo J, Anderson J, Brook RD, et al. Fluticasone furoate and vilanterol and survival in chronic obstructive pulmonary disease with heightened cardiovascular risk (SUMMIT): a double-blind randomised controlled trial. Lancet 2016; 387: 1817-1826.

13 Celli B, Decramer M, Kesten S, et al. Mortality in the 4-year trial of tiotropium (UPLIFT) in patients with chronic obstructive pulmonary disease. Am J Respir Crit Care Med 2009; 180: 948-955.

14 Viskin S, Barron HV. Beta blockers prevent cardiac death following a myocardial infarction: so why are so many infarct survivors discharged without beta blockers? Am J Cardiol 1996; 78: 821-822.

15 Buhl R, Maltais F, Abrahams R, et al. Tiotropium and olodaterol fixed-dose combination versus mono-components in COPD (GOLD 2-4). Eur Respir J 2015; 45: 969-979.

16 Oba Y, Sarva ST, Dias S. Efficacy and safety of long-acting beta-agonist/long-acting muscarinic antagonist combinations in COPD: a network meta-analysis. Thorax 2016; 71: 15-25.

17 Novartis. FLAME study shows superiority of Novartis' Ultibro ${ }^{\circledR}$ Breezhaler $^{\circledR}$ over Seretide ${ }^{\circledR}$ in reducing COPD exacerbations. https://www.novartis.com/news/media-releases/flame-study-shows-superiority-novartis-ultibro\%C2\% AE-breezhaler\%C2\%AE-over-seretide\%C2\%AE Date last updated: November 17, 2015.

18 Pascoe S, Locantore N, Dransfield MT, et al. Blood eosinophil counts, exacerbations, and response to the addition of inhaled fluticasone furoate to vilanterol in patients with chronic obstructive pulmonary disease: a secondary analysis of data from two parallel randomised controlled trials. Lancet Respir Med 2015; 3: 435-442.

19 Barnes NC, Sharma R, Lettis S, et al. Blood eosinophils as a marker of response to inhaled corticosteroids in COPD. Eur Respir J 2016.

20 Christenson SA, Steiling K, van den Berge M, et al. Asthma-COPD overlap. Clinical relevance of genomic signatures of type 2 inflammation in chronic obstructive pulmonary disease. Am J Respir Crit Care Med 2015; 191 758-766.

21 Dransfield MT, Bourbeau J, Jones PW, et al. Once-daily inhaled fluticasone furoate and vilanterol versus vilanterol only for prevention of exacerbations of COPD: two replicate double-blind, parallel-group, randomised controlled trials. Lancet Respir Med 2013; 1: 210-223.

22 Kew KM, Seniukovich A. Inhaled steroids and risk of pneumonia for chronic obstructive pulmonary disease. Cochrane Database Syst Rev 2014; 3: CD010115.

23 Tashkin DP, Celli B, Senn S, et al. A 4-year trial of tiotropium in chronic obstructive pulmonary disease. $N$ Engl J Med 2008; 359: 1543-1554.

24 Suissa S, Patenaude V, Lapi F, et al. Inhaled corticosteroids in COPD and the risk of serious pneumonia. Thorax 2013; 68: 1029-1036.

25 Janson $\mathrm{C}$, Larsson K, Lisspers $\mathrm{KH}$, et al. Pneumonia and pneumonia related mortality in patients with COPD treated with fixed combinations of inhaled corticosteroid and long acting $\beta 2$ agonist: observational matched cohort study (PATHOS). BMJ 2013; 346: f3306.

26 Jimenez-Ruiz CA, Andreas S, Lewis KE, et al. Statement on smoking cessation in COPD and other pulmonary diseases and in smokers with comorbidities who find it difficult to quit. Eur Respir J 2015; 46: 61-79.

27 Andreas S, Anker SD, Scanlon PD, et al. Neurohumoral activation as a link to systemic manifestations of chronic lung disease. Chest 2005; 128: 3618-3624. 